\title{
Lymphocytic hypophysitis causing hypopituitarism and diabetes insipidus, and associated with autoimmune thyroiditis, in a non-pregnant woman
}

\author{
M. Paja, J. Estrada, A. Ojeda, S. Ramón y Cajal' J. García-Uría ${ }^{2}$ and T. Lucas \\ Departments of Endocrinology, ${ }^{1}$ Pathology and ${ }^{2}$ Neurosurgery, Clínica Puerta de Hierro, San Martin de \\ Porres 4, 28035 Madrid, Spain
}

\begin{abstract}
Summary: A 25 year old non-pregnant woman presented with a one-year history of amenorrhoea and polyuria. Three months before her admission, she had suffered lymphocytic meningitis. Hormonal studies revealed hypopituitarism and central diabetes insipidus, with associated primary autoimmune hypothyroidism. Computed tomographic scan and magnetic resonance imaging showed a pituitary mass with suprasellar extension and thickened stalk. Transsphenoidal surgery was performed and the histological study revealed fibrosis and diffuse lymphocytic infiltration with predominance of CD4 lymphocytes. This further case of lymphocytic hypophysitis was not related to pregnancy and produced diabetes insipidus, two uncommon associations. We discuss the features that can lead to a preoperative suspicion of this rare disorder.
\end{abstract}

\section{Introduction}

Lymphocytic hypophysitis is a rare autoimmune process first reported by Goudie and Pinkerton in $1962 .{ }^{1}$ Since then, about 50 cases have been documented, most of them in women and having a close temporal relationship to pregnancy. Only three cases occurred in men, ${ }^{2-4}$ and another three in premenopausal women who had never been pregnant..$^{5-7}$ Clinically, it is characterized by symptoms of compressive sellar mass, together with varying degrees of hypopituitarism, usually without involvement of the neurohypophysis. ${ }^{4,5,8,9}$ It is often associated with other autoimmune phenomena. Histologically, the anterior pituitary presents a plasmacytoid lymphocytic infiltrate accompanied by oedema and fibrosis, in addition to small islands of normal pituitary cells.

We report a further case of lymphocytic hypophysitis in a 25 year old non-pregnant, nulliparous woman, producing panhypopituitarism and diabetes insipidus and associated with autoimmune thyroiditis. The clinical, radiological, serological and histological features are described and compared with previously reported cases. We also discuss the signs that may lead to the preoperative suspicion of this disorder.

Correspondence: M. Paja Fano, M.D.

Accepted: 12 August 1993

\section{Case report}

A 25 year old woman was referred to us for evaluation of a possible pituitary tumour. For the preceding 11 months, she had been amenorrhoeic and had presented increasing polyuria, with diuresis of up to 10 litres a day. Three months prior to her admission, she had had a sudden episode of fever $\left(38.5^{\circ} \mathrm{C}\right)$, somnolence and vomiting, requiring hospital admission. Blood cultures were negative and lumbar puncture yielded a sample of cerebrospinal fluid (CSF) with 600 cells $/ \mu \mathrm{l}, 45 \% \mathrm{lym}$ phocytes, protein levels of $0.74 \mathrm{~g} / 1$ and glucose level of $2.3 \mathrm{mmol} / 1$ ( $4.7 \mathrm{mmol} / 1$ in blood). The cultures, Ziehl-Neelsen stain and latex agglutination test for cryptococcal antigen were negative, as was serology for Brucella, Lyme's disease (Borrelia burgdorferi), Cryptococcus and VDRL, both in serum and CSF. Fever and the meningeal syndrome disappeared with conservative treatment. She underwent cranial computed tomography (CT) scan, which revealed an enlarged pituitary gland containing hypodense areas and exhibiting suprasellar extension (Figure 1).

On presentation, she was asthenic, with polyuria and polydipsia with pronounced nocturia, and she remained amenorrhoeic. She had never been pregnant. Her symptoms included orthostatic hypotension and increased sensitivity to cold over the 


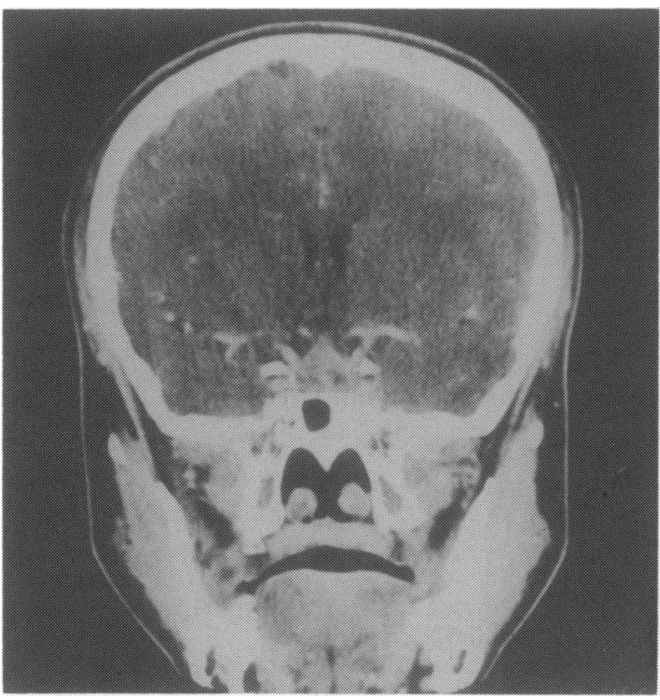

Figure 1 Coronal CT image showing enlarged pituitary gland with expansion to the suprasellar cistern.

preceding year. Blood pressure was $105 / 60 \mathrm{mmHg}$ and heart rate 50 beats/minute. The skin was dry, the thyroid gland not palpable and there was no galactorrhea. There was no evidence of acromegaly or Cushing's syndrome. Initial analysis revealed a white cell count of $7 \times 10^{9} / 1$ (47\% lymphocytes) and an ESR of $30 \mathrm{~mm}$ in the first hour. Serum biochemistry showed a total cholesterol level of $7.2 \mathrm{mmol} / 1$ (normal range 3.9-5.7) and a potassium level of $5.1 \mathrm{mmol} / 1$ (normal range $3.5-5.0$ ); other parameters, including liver function tests and calcium levels were normal. The results of the protein assays and the quantification of serum immunoglobulins were normal except for a slight elevation in the $\alpha_{2}$-globulin fraction. Electrocardiogram disclosed bradycardia at 54 r.p.m. A chest $\mathrm{X}$-ray was normal. Skull X-rays showed enlarged sella turcica (grade II). ${ }^{10}$ Magnetic resonance imaging (MRI) revealed an intrasellar mass with suprasellar extension, slightly displacing the optic chiasm (Figure 2), while in the sagittal section, a hypertrophic pituitary stalk could be detected, with a small area of high intensity before the dorsum sellae which may have corresponded to the posterior pituitary lobe (Figure 3). Perimetric study and ocular fundus were normal. Serum $\beta$-human chorionic gonadotrophin (HCG) and $\alpha$-fetoprotein were undetectable. There was no evidence of pathological uptake on bone scintigraphy. Endocrinological evaluation revealed hypothyroidism, adrenal insufficiency, hypogonadism and decreased growth hormone $(\mathrm{GH})$ secretion, with a slightly elevated prolactin (PRL) level (Table I). Partial

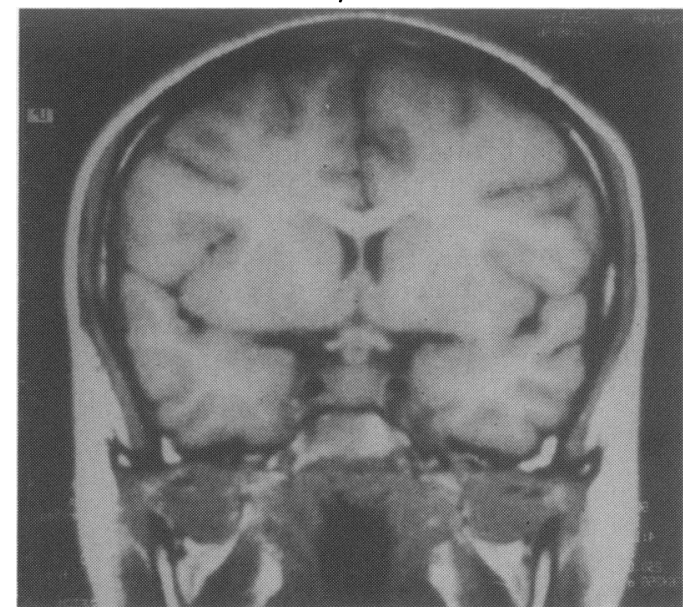

Figure 2 Coronal magnetic resonance (MR) image showing the occupation of the sella turcica by an isointense mass which continues along the hypophyseal stalk.

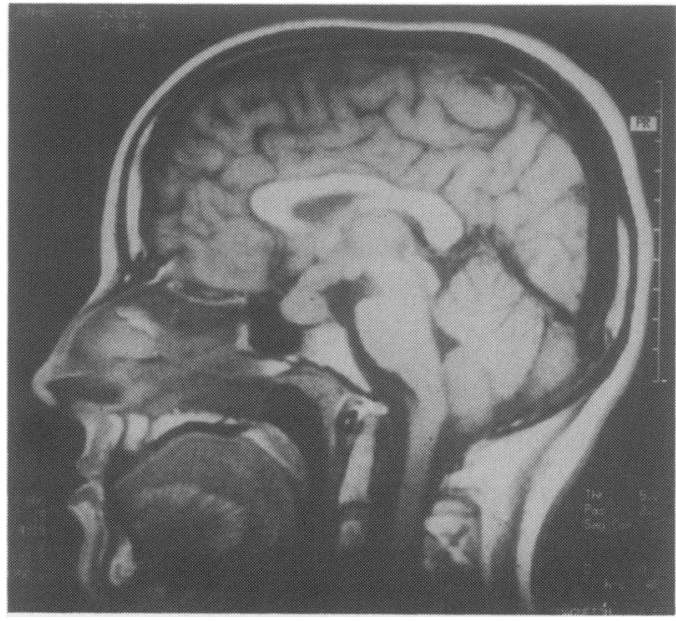

Figure 3 Sagittal MR image showing hypertrophic pituitary stalk and minimal neurohypophyseal signal.

central diabetes insipidus was confirmed by Miller's test, in which plasma osmolality rose to $298 \mathrm{mosmol} / \mathrm{kg}$ after 12 hours of water deprivation, with a simultaneous urinary osmolality of $320 \mathrm{mosmol} / \mathrm{kg}$, which increased to $364 \mathrm{mosm} / \mathrm{kg}$ $(+13.7 \%)$ after subcutaneous administration of 5 IU of aqueous vasopressin. Radioimmunoassay detected antibodies to thyroglobulin at titres of 1:15,300 and anti-thyroid microsomes (peroxidase) 
at 1:102,400. Anti-pituitary antibodies, tested by indirect immunofluorescence on frozen sections of normal monkey pituitary tissue, were not found.

After 4 weeks of replacement therapy with L-thyroxine, hydrocortisone and desmopressin, the patient underwent trans-sphenoidal surgery. A soft, whitish unencapsulated mass with welldefined borders was found. It extended to the sellar diaphragm, separated from it by a clear cleavage plane. After its complete removal, the pathological examination revealed abundant lymphocytic infiltrate, with no giant cells or granulomas, together with extensive areas of hyalinized fibroblastic tissue and islands of pituitary cells. Glandular islets with acidophilic cells and intra-epithelial lymphocytes were observed focally (Figure 4). Neurohypophysis was not identified. Isolated growth hormone-positive cells were detected (Dakopatts) in the immunohistochemical study but no positive cells were observed for the other pituitary hormones. The lymphocytic infiltrate consisted of B cells (antibody L26, Dakopatts) and numerous $T$ lymphocytes (antibodies UCHL-1 and MT-1) with predominance of CD4 cells over CD8 (OKT4 and OKT8, Ortho, frozen slices). In the ultrastructural study, abundant lymphoid cells were identified as were

Table I Response to combined intravenous injection of thyrotrophin-releasing hormone ( $400 \mu \mathrm{g})$, luteinizing hormone-releasing hormone $(100 \mu \mathrm{g})$ and insulin $(0.1 \mathrm{U} / \mathrm{kg})$

\begin{tabular}{lccccccc}
\hline & $\begin{array}{c}\text { Glucose } \\
(\text { mmol/l) }\end{array}$ & $\begin{array}{c}G H \\
(\mu g / l)\end{array}$ & $\begin{array}{c}\text { Cortisol } \\
(\text { nmol/l) }\end{array}$ & $\begin{array}{c}\text { TSH } \\
(\mathrm{mU} / \mathrm{l})\end{array}$ & $\begin{array}{c}\text { PRL } \\
(\mu g / l)\end{array}$ & $\begin{array}{c}\text { LH } \\
(I U / l)\end{array}$ & $\begin{array}{c}F S H \\
(I U / l)\end{array}$ \\
\hline $\begin{array}{l}\text { Preoperative } \\
\text { B/P }\end{array}$ & $4.8 / 2.2$ & $1.7 / 2.6$ & $58 / 336$ & $13 / 76$ & $40 / 66$ & $1 / 4.3$ & $1.4 / 5.2$ \\
$\begin{array}{l}\text { Postoperative } \\
\text { B/P }\end{array}$ & $3.8 / 1.6$ & $0.3 / 1.3$ & $30 / 36$ & $11 / 32$ & $13 / 18$ & $0.5 / 2$ & $0.1 / 0.4$ \\
\hline
\end{tabular}

$\mathrm{B}=$ basal; $\mathrm{P}=$ peak $; \mathrm{GH}=$ growth hormone; $\mathrm{TSH}=$ thyroid stimulating hormone; $\mathrm{PRL}=$ prolactin; $\mathrm{LH}=$ luteinizing hormone; FSH $=$ follicle stimulating hormone.
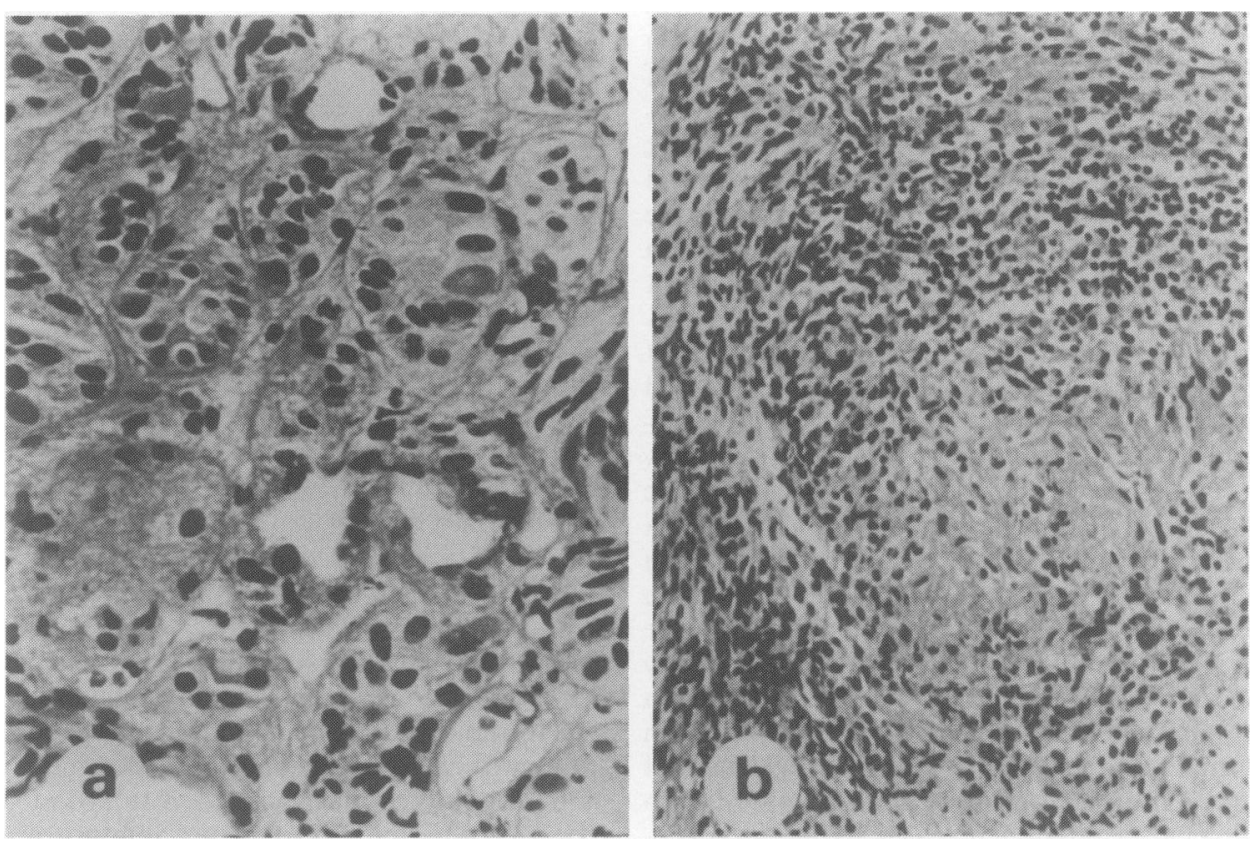

Figure 4 (a) Detail of some acini of the pituitary gland, showing lymphocytes within the epithelial cells and reactive and degenerative changes (H \& E $\times 400)$. (b) Most of the pituitary gland was composed of connective tissue with prominent inflammatory infiltrate and absence of acini $(\mathrm{H} \& \mathrm{E} \times 250)$. 
occasional endocrine cells, with medium-sized granules. These findings were diagnostic for lymphocytic hypophysitis.

The results of immunological studies performed after surgery in peripheral blood were as follows: CD4 55\%, CD8 16\%, CD4/CD8 3.44, CD20 (B1) $18 \%$, and CD14 (Mo2) $5 \%$. Antibodies to nuclear antigen, DNA, smooth muscle, mitochondria, ovary, adrenal gland, islet cells and gastric parietal cells were all negative. Following surgery, hypopituitarism in diabetes insipidus persisted (Table I), while the prolactin fell to normal levels.

\section{Discussion}

Since the first reports of diagnoses of lymphocytic hypophysitis in life, ${ }^{11,12}$ this disorder has been included in the differential diagnosis of sellar masses. Initially, it was suspected only in women, but recently, after its identification in an impotent male in $1987,{ }^{2}$ it has also been considered in the differential diagnosis in men. Of the 47 histologically confirmed cases reviewed in the English and French-language literature, three involved males, ${ }^{2-4}$ and three occurred in premenopausal nulliparous women. ${ }^{5-7}$ Two of the latter sought medical attention owing to secondary amenorrhoea and the third because of infertility with normal menses. Most patients complained of symptoms suggestive of sellar mass, headache and visual disorders, in addition to symptoms of antehypophyseal deficits. ${ }^{13}$ Only five cases were associated with diabetes insipidus, ${ }^{4-7}$ which was transitory in one. ${ }^{7}$ Our patient was of child-bearing age, had never been pregnant and presented with central diabetes insipidus, all of which constitute unusual findings.

She had suffered lymphocytic meningitis three months earlier, an event which has occurred in two previous cases. ${ }^{4,9}$ The meningitis-inducing virus has been proposed as the aetiological factor in lymphocytic hypophysitis, acting by means of an immunological cross-reaction between viral and hypophyseal antigens. ${ }^{9}$ This sequence of events did not seem likely in our patient, since she had an 11-month history of amenorrhoea and diabetes insipidus. The meningeal syndrome could have been caused by the hypophysitis-related passage of the infiltrate into the subarachnoid space.

The panhypopituitarism appearing in our patient could be the consequence of the destruction of the hypophyseal parenchyma, although the presence of hyperprolactinaemia suggests that the infiltration of the hypophyseal stalk may also play a role by interfering with the delivery of hypothalamic hormones. The hormonal study revealed slightly elevated basal thyrotrophin (TSH) levels, with low free thyroxine $(5.66 \mathrm{pmol} / \mathrm{l}$; normal range
10.3-25.7), hyper-response of TSH to thyrotrophin-releasing hormone (TRH) stimulus and antithyroid antibodies, all of which is diagnostic for chronic thyroiditis and primary hypothyroidism, combined with a reduction in the TSH reserve.

Suprasellar extension of the tumour (occurring in up to $75 \%$ of cases) is commonly disclosed by CT and magnetic resonance imaging (MRI); the thickening of the hypophyseal stalk found in our patient was also detected by MRI in other reported cases. ${ }^{4,5,14}$ Although in diabetes insipidus of organic origin, the image of the posterior pituitary lobe can not be viewed with MRI, ${ }^{15}$ in our case, the presence of an attenuated signal is coherent with the partial nature of the diabetes insipidus.

Our case presented features, such as the presence of diabetes insipidus and stalk thickening, that are unusual in hypophyseal adenomas. Therefore, the differential diagnosis required additional studies to rule out other processes: intrasellar germ-cell tumour markers ${ }^{16}$ and bone scintigraphy for Langerhans cell histiocytosis, although the latter was improbable in view of the appearance of the posterior hypophyseal lobe in MRI. ${ }^{17}$

The presence of lymphocytes lacking granulomas and giant foreign body cells in the excised mass leads to the definitive diagnosis of lymphocytic hypophysitis. Some authors have found additional cell populations such as neutrophils, ${ }^{2,18-21}$ while others propose a relationship between granulomatous hypophysitis and lymphocytic hypophysitis, ${ }^{22}$ considering them to be two phases of the same disease. The exhaustive histological study of the surgical specimen ruled out the presence of granulomas in our case. Having found a sequential onset of lymphocytic hypophysitis, and ocular and pulmonary sarcoidosis in one patient, Hayashi ${ }^{23}$ proposes that abnormal autoimmune processes may be involved in the development of both disorders. Although the histological coincidence of the two disorders has also been reported,$^{24}$ there was no evidence of sarcoidosis in our case.

The autoimmune pathogenesis of lymphocytic hypophysitis is demonstrated by the increment in the $C D 4 / C D 8$ ratio in the peripheral blood $T$ lymphocytes, as well as the predominance of the CD4 subpopulation among the infiltrating lymphocytes. These same results, both in peripheral blood $^{5,23,25}$ and in the infiltrate ${ }^{7,25,26}$ have been reported previously. The association of lymphocytic hypophysitis with other autoimmune processes, mainly thyroiditis, ${ }^{1,26-29}$ lends further support to the evidence indicating this origin.

In summary, we have reported a new patient with lymphocytic hypophysitis producing hypopituitarism and diabetes insipidus, associated with chronic thyroiditis. In our opinion, this diagnosis should be suspected when there is a sellar mass 
accompanied by thickening of the hypophyseal stalk and MRI signal of the neurohypophysis, especially in a woman who is or has been pregnant. The presence of other autoimmune diseases and the rise in the peripheral blood $\mathrm{CD} 4 / \mathrm{CD} 8$ ratio increase the suspicion of this diagnosis. Antihypophyseal antibodies are rarely detected. The importance of a presurgical diagnosis lies in the possibility of achieving a response to steroid treat-

\section{References}

1. Goudie, R.B. \& Pinkerton, P.H. Anterior hypophysitis and Hashimoto's disease in a young woman. $J$ Pathol Bacteriol 1962, 83: 584-585.

2. Guay, A.T., Agnello, V., Tronic, B.C., Gresham, D.G. \& Freidberg, S.R. Lymphocytic hypophysitis in a man. J Clin Endocrinol Metab 1987, 64: 631-634.

3. Pestell, R.G., Best, J.D. \& Alford, F.P. Lymphocytic hypophysitis. The clinical spectrum of the disorder and evidence for an autoimmune pathogenesis. Clin Endocrinol 1990, 33: 457-466.

4. Nussbaum, C.E., Okawara, S.H. \& Jacobs, L.S. Lymphocytic hypophysitis with involvement of the cavernous sinus and hypothalamus. Neurosurgery 1991, 28: 440-444.

5. Miura, M., Ushio, Y., Kuratsu, J.I., Ikeda, J.I., Kai, Y. \& Yamashiro, S. Lymphocytic adenohypophysitis: report of two cases. Surg Neurol 1989, 32: 463-470.

6. Wild, R.A. \& Kepley, M. Lymphocytic hypophysitis in a patient with amenorrhea and hyperprolactinemia. A case report. J Reprod Med 1986, 31: 211-216.

7. McCutcheon, I.E. \& Oldfield, E.H. Lymphocytic adenohypophysitis presenting as infertility. $J$ Neurosurg 1991,74 $8221-8226$.

8. McDermott, M.W., Greisdale, D.E., Berry, K. \& Wilkins, G.E. Lymphocytic adenohypophysitis. Can J Neurol Sci 1988, 15: 38-43.

9. Vanneste, J.A.L. \& Kamphorst, W. Lymphocytic hypophysitis. Surg Neurol 1987, 28: 145-149.

10. Vezina, J.L. \& Maltais, R. La selle turcique dans l'acromegalie. Etude radiologique. Neurochirugie 1973, 19 (Suppl 2): 35-56.

11. Quencer, R.M. Lymphocytic adenohypophysitis: autoimmune disorder of the pituitary gland. $A J N R$ 1980, 1: 343-345.

12. Mayfield, R.K., Levine, J.H., Gordon, L., Powers, J., Galbraith, R.M. \& Rawe, S.E. Lymphoid adenohypophysitis presenting as pituitary tumor. Am J Med 1980, 69: 619-623.

13. Cosman, F., Post, K.D., Holub, D.A. \& Wardlaw, S.L. Lymphocytic hypophysitis. Report of three new cases and review of the literature. Medicine 1989, 68: 240-256.

14. Levine, S.N., Benzel, E.C., Fowler, M.R., Shroyer, J.V. \& Mirfakhraee, M. Lymphocytic adenohypophysitis: clinical, radiological, and magnetic resonance imaging characterization. Neurosurg 1988, 22: 937-941.

15. Maghnie, M., Villa, A., Arico, M. et al. Correlation between magnetic resonance imaging of posterior pituitary and neurohypophyseal function in children with diabetes insipidus. J Clin Endoc Metab 1992, 74: 795-800.

16. Neuwelt, E.A., Frenkel, E.P. \& Smith, R.G. Suprasellar germinomas (ectopic pinealomas): aspects of immunological characterization and successful chemotherapeutic responses in recurrent disease. Neurosurgery 1980, 7: 352-358.

17. Tien, R.D., Newton, T.H., McDermott, M.W., Dillon, W.P. \& Kucharzyk, J. Thickened pituitary stalk on MR images in patients with diabetes insipidus and Langerhans cell histiocytosis. AJNR 1990, 11: 703-708. ment, with reduction of the mass, ${ }^{30,31}$ and in the performance of minimally aggressive surgery in the attempt to preserve hypophyseal function when the patient's vision has not been jeopardized.

\section{Acknowledgements}

The authors wish to thank Ms M. Messman for her translation of the text.
18. Asa, S.L., Bilbao, J.M., Kovacs, K., Josse, R.G. \& Kreines, K. Lymphocytic hypophysitis of pregnancy resulting in hypopituitarism: a distinct clinicopathologic entity. Ann Intern Med 1981, 95: 360-363.

19. Baskin, D.S., Townsend, J.J. \& Wilson, C.B. Lymphocytic adenohypophysitis of pregnancy simulating a pituitary adenoma: a distinct pathological entity. Report of two cases. $J$ Neurosurg 1982, 56: 148-153.

20. Cebelin, M.S., Velasco, M.E., De Las Mulas, J.M. \& Druet, R.L. Galactorrhea associated with lymphocytic adenohypophysitis. Case report. Br J Obstet Gynecol 1981, 88: 675-680.

21. Portocarrero, C.J., Robinson, A.G., Taylor, A.L. \& Klein, I. Lymphoid hypophysitis. An unusual cause of hyperprolactinemia and enlarged sella turcica. JAMA 1981, 246: 1811-1812.

22. McKeel, D.W. Primary hypothyroidism and hypopituitarism in a young woman. Am J Med 1984, 77: 319-330.

23. Hayashi, H., Yamada, K., Kuroki, T. et al. Lymphocytic hypophysitis and pulmonary sarcoidosis. Report of a case. AJCP 1991, 95: 506-511.

24. Miyamoto, M., Sugawa, H., Mori, T., Hashimoto, N. \& Imura, $\mathrm{H}$. A case of hypopituitarism due to granulomatous and lymphocytic adenohypophysitis with minimal pituitary enlargement: a possible variant of lymphocytic adenohypophysitis. Endocrinol Jap 1988, 35: 607-616.

25. Hashimoto, M., Yanaki, T., Nakahara, N. \& Masuzawa, T. Lymphocytic adenohypophysitis: an immunohistochemical study. Surg Neurol 1991, 36: 137-144.

26. Jensen, M.D., Handwerger, B.S., Bernd, W.S., Carpenter, P.C., Mirakian, R. \& Banks, P.M. Lymphocytic hypophysitis with isolated corticotropin deficiency. Ann Intern Med 1986, 105: 200-203.

27. Hume, R. \& Roberts, G.H. Hypophysitis and hypopituitarism: report of a case. Br Med J 1967, 2: 548-550.

28. Richtsmeier, A.J., Henry, R.A., Blooworth, J.M.B. \& Ehrlich, E.N. Lymphoid hypophysitis with selective adrenocorticotrophic hormone deficiency. Arch Intern Med 1980, 140: 1243-1245.

29. Gal, R., Schwartz, A., Gukowsky-Oren, S., Peleg, D., Goldman, J. \& Kessler, E. Lymphoid hypophysitis associated with sudden maternal death: report of a case and review of the literature. Obstet Gynecol Surv 1986, 41: 619-621.

30. McGrail, K.M., Beyerl, B.D., Black, P.M., Klibansky, A. \& Zerbas, N.T. Lymphocytic adenohypophysitis of pregnancy with complete recovery. Neurosurgery 1987, 20: 791-793.

31. Bitton, R.N., Slavin, M., Decker, R.E., Zito, J. \& Schneider, B.S. The course of lymphocytic hypophysitis. Surg Neurol 1991, 36: 40-43. 